\title{
Evolução da maturação da uva 'BRS Clara' sob cultivo protegido durante a safra fora de época
}

\author{
Lilian Yukari Yamamoto ('); Adriane Marinho de Assis ( ${ }^{2}$ ); Heverly Morais (3); Fábio Suano de Souza (4); \\ Lidiane Carla Vilanova Miotto ('); Alessandro Jefferson Sato ('); Reginaldo Teodoro de Souza (5); Sérgio \\ Ruffo Roberto $\left(2^{*}\right)$
}

(') Universidade Estadual de Londrina (UEL), Programa de Pós-Graduação em Agronomia, Caixa Postal 6001, 86051-990 Londrina (PR), Brasil.

(2) UEL, Departamento de Agronomia/Fitotecnia, 86051-990 Londrina (PR), Brasil.

(3) Instituto Agronômico do Paraná, Caixa Postal 481, 86047-902 Londrina (PR), Brasil.

(4) Centro Universitário Filadélfia, Av. JK, 1626, 86020-000 Londrina (PR), Brasil.

(5) Embrapa Uva e Vinho, Caixa Postal 241, 15700-000 Jales (SP), Brasil.

(*) Autor correspondente: sroberto@uel.br

Recebido: 8/abr./2011; Aceito: 26/ago./2011

\begin{abstract}
Resumo
A produção de uvas para mesa vem passando por alguns desafios que demandam alterações nas tecnologias de produção, devido, principalmente, à intensa necessidade de controle de doenças fúngicas. O objetivo deste trabalho foi avaliar o comportamento da evolução da maturação da uva 'BRS Clara' enxertada sobre o porta-enxerto IAC 766 'Campinas', sob cultivo protegido produzida em safra fora de época. Os experimentos foram realizados em Uraí e Marialva (PR). Foram avaliadas semanalmente as características químicas das bagas, como teor de sólidos solúveis, acidez titulável, índice de maturação e pH, a partir do início da maturação até a colheita, em dois sistemas de cultivo protegido: cobertura plástica e sombrite. O delineamento experimental adotado em ambas as áreas foi o inteiramente casualizado com sete repetições. A evolução da maturação nos dois sistemas de cultivo protegido foi comparada por meio da análise de regressão. Em ambas as áreas experimentais, a cobertura plástica possibilitou a antecipação da colheita das uvas em seis dias em relação ao sombrite, considerando o teor de sólidos solúveis. Não houve influência da cobertura plástica sobre o índice de maturação das uvas.
\end{abstract}

Palavras-chave: Uva apirena, cultivo protegido, maturação, Plasmopara viticola.

\section{Ripening evolution of 'BRS Clara' grape under protected cultivation during out of season crop}

\section{Abstract}

The production of table grapes has been facing some challenges that require changes in production technologies, primarily due to the intense need to control fungal diseases. The aim of this study was to evaluate the ripening of 'BRS Clara' grapevines grafted on IAC 766 'Campinas' rootstock, under protected cultivation grown out of season. The experiments were performed at Uraí and Marialva, Paraná State, Brazil. The chemical characteristics of the berries such as soluble solids, titratable acidity, maturation index and $\mathrm{pH}$ were evaluated weekly from early ripening to harvesting, in two protected cultivation systems: under plastic cover and under plastic screen. The randomized design was used as a statistical model, in both experiments, with seven replications. The berry ripening evolution was compared by means of regression analysis. In both experimental areas, the plastic cover enabled earlier grape harvest (in six days) as compared to the plastic screen, being the harvest based on the soluble solids content. The plastic cover did not modify the maturation index of the berries of 'BRS Clara'.

Key words: Seedless grape, protected cultivation, ripening, Plasmopara viticola. 


\section{INTRODUÇÃO}

O cultivo da videira no Paraná abrange aproximadamente 5.800 ha, com produção de 102.080 toneladas em 2009. As regiōes Norte e Noroeste são responsáveis por, aproximadamente, $20 \%$ do total da área cultivada por uvas para mesa no Brasil, onde tradicionalmente são produzidas as uvas 'Itália', 'Rubi', 'Benitaka' e 'Brasil' (Kishino et al., 2007; IвGE, 2009). No entanto, verifica-se no país o mercado crescente de uvas sem sementes, impulsionado pela preferência dos consumidores (LuLu et al., 2005).

Dentre as uvas sem sementes, a 'BRS Clara', obtida por meio do cruzamento entre as uvas '154-147' x 'Centennial Seedless', em 1998, pela Embrapa Uva e Vinho, é uma cultivar vigorosa e fértil, adaptada ao cultivo nas regiôes tropicais. Além disso, possui suave e agradável sabor moscatel, coloração verde-amarelada e textura crocante da polpa (CAMARGo et al., 2003).

Uma das características da viticultura nas regiôes Norte e Noroeste do Paraná é a obtenção de dupla safra em um ano, com a realização da primeira colheita de dezembro a janeiro e da segunda colheita, entre maio e junho, período em que a oferta de uvas para mesa no Brasil em outras regiôes é baixa ou inexistente (Kishino et al., 2007). Contudo, principalmente durante a safra fora de época, boa parte do ciclo produtivo da videira ocorre no período chuvoso, quando a temperatura e a umidade relativa são mais elevadas. Essas condiçôes são propícias à ocorrência de doenças fúngicas, como o míldio (Plasmopara viticola), que podem causar perdas até de $100 \%$ da produção, se não forem adotadas medidas adequadas de controle (NAVES et al., 2005; Kishino et al., 2007). Assim, o custo de produção de uvas finas para mesa tem sido afetado, principalmente, pela intensa necessidade de controle de doenças.

Uma alternativa que vem sendo empregada para minimizar este problema é o uso da cobertura plástica, que tem como principais vantagens: redução dos tratamentos fitossanitários, obtenção de frutos de melhor qualidade, economia de insumos e conservação do solo, além da valorizaçáo comercial do produto, pela obtençáo de colheitas fora de época (Detoni et al., 2007).

$\mathrm{O}$ uso da cobertura plástica nos vinhedos tem sido estudado por alguns autores (Lulu et al., 2005; Novello e Palma, 2008; Chavarria et al., 2009b; Colombo et al., 2011; Genta et al., 2010), com resultados satisfatórios para as uvas destinadas ao consumo in natura. Entretanto, nas regióes Norte e Noroeste do Paraná, o cultivo de videiras é realizado com o uso do sombrite em mais de $95 \%$ das propriedades rurais, evidenciando a necessidade de pesquisas no intuito de averiguar a eficácia do sistema de produção de uvas sob cobertura plástica, pois conforme verificado por Ferreira et al. (2004), Detoni et al. (2007) e Chavarria et al. (2010), esse tipo de cobertura, em algumas situações, pode modificar a composição química das bagas.
Diante desses aspectos, o objetivo deste trabalho foi avaliar as características químicas e a evolução da maturação das bagas da videira 'BRS Clara', cultivada sob cobertura plástica, durante a safra fora de época, no Norte do Paraná.

\section{MATERIAL E MÉTODOS}

Foi avaliada a evolução da maturação da uva 'BRS Clara', enxertada sobre o porta-enxerto IAC 766 'Campinas', em dois sistemas de cultivo protegido, sob cobertura plástica e sob sombrite.

O primeiro experimento foi realizado de janeiro a maio de 2009, em vinhedo comercial localizado no município de Uraí (PR) (2314'33,9”' S, 5046'55,5' O e altitude $438 \mathrm{~m}$ ). Segundo a classificação de Köppen, o clima da regiáo é do tipo Cfa (Clima subtropical), com temperatura média no mês mais frio inferior a $18{ }^{\circ} \mathrm{C}$ e temperatura média no mês mais quente acima de $22^{\circ} \mathrm{C}$, sendo a precipitação pluvial média anual de $1.507 \mathrm{~mm}$ (CAviglione et al., 2000). O solo desta região é classificado como Nitossolo Vermelho Eutroférrico.

O plantio do porta-enxerto e a enxertia da variedade copa foram realizados em julho de 2004 e 2005 respectivamente, utilizando-se material propagativo livre de vírus obtido na Embrapa Uva e Vinho, Bento Gonçalves (RS). As videiras foram sustentadas no sistema de pérgola, em espaçamento de 4,0 x 4,0 m.

A poda longa de frutificação, deixando-se seis a oito gemas por vara, foi realizada em 14 de janeiro de 2009, e em seguida, aplicou-se cianamida hidrogenada a $2,5 \%$, sobre as duas gemas apicais para a uniformizar a brotação. Aos vinte dias após o florescimento, foi aplicado por pulverização o ácido giberélico a $33 \mathrm{mg} \mathrm{L}^{-1}$ sobre os cachos, para promover o engrossamento do racemo e o aumento do tamanho da baga.

No sistema de cultivo protegido com cobertura plástica foram utilizadas lonas plásticas transparentes de polietileno trançado, de $20 \%$ de sombreamento, com 5,0 $\mathrm{m}$ de largura e $150 \mathrm{~m} \mu$ de espessura, aditivadas contra raios ultravioleta e antigotejo, modelo TEC 5000 (Terra Toledo Coberturas, Caxias do Sul, RS).

A cobertura plástica foi instalada sobre fios metálicos e arcos de ferro galvanizado com 5,0 m de comprimento, dispostos no parreiral a cada 3,0 m, os quais, por sua vez, foram fixados sobre a estrutura de postes de eucalipto, que propicia a sustentação e forma ao sistema de condução. $\mathrm{O}$ ponto mais alto da cobertura plástica ficou a uma distância de $1,2 \mathrm{~m}$ em relação às videiras. As cortinas laterais da área do experimento foram mantidas com sombrite.

Nas videiras cultivadas sob sombrite no sistema de capela, utilizou-se tela de polietileno preta, com $23 \%$ de retenção de fluxo de radiação solar, sustentada pelos fios de arame da latada, sem a utilização de arcos. 
A irrigação por aspersão foi realizada abaixo da copa das videiras, em quantidade suficiente para o desenvolvimento adequado das plantas e os tratos culturais foram efetuados de acordo com as recomendaçôes técnicas para a região (Kishino et al., 2007). Com relação às aplicaçôes de produtos fitossanitários, foram realizadas 16 e 39 aplicaçôes para o controle do míldio, respectivamente, nas videiras cultivadas sob cobertura plástica e sob sombrite, de acordo com o critério do consultor técnico da área.

O segundo experimento foi realizado no período de janeiro a maio de 2010 , em vinhedo comercial localiza-

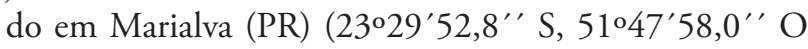
e altitude $570 \mathrm{~m}$ ). Segundo a classificação de Köppen, o clima da região é do tipo Cfa (Clima subtropical), com temperatura média no mês mais frio inferior a $18^{\circ} \mathrm{C}$ (mesotérmico) e temperatura média no mês mais quente acima de $22^{\circ} \mathrm{C}$, sendo a precipitação pluvial média anual de $1.596 \mathrm{~mm}$ (CAViglione et al., 2000). O solo desta regiáo é classificado como Latossolo Vermelho distroférrico.

O plantio do porta-enxerto e a enxertia da variedade copa foram realizadas em julho de 2003 e 2004 respectivamente, utilizando-se material propagativo livre de vírus obtido na Embrapa Uva e Vinho, Bento Gonçalves (RS). As videiras foram sustentadas no sistema de pérgola, em espaçamento de 2,0 x 5,0 m.

A poda longa de frutificação, deixando-se seis a oito gemas por vara, foi realizada em 13 de janeiro de 2010 e, em seguida, aplicou-se cianamida hidrogenada a 2,5\%, sobre as duas gemas apicais no intuito de uniformizar a brotação das gemas. Aos vinte dias após o florescimento aplicou-se por pulverização o ácido giberélico a $50 \mathrm{mg} \mathrm{L}^{-1}$ sobre os cachos, sendo reaplicado cinco dias após, para propiciar o engrossamento do racemo e o aumento do tamanho da baga.

No sistema de cultivo protegido com cobertura plástica, utilizou-se o mesmo material do experimento realizado em Uraí, sendo instalado no mesmo período, diferindo somente nas dimensôes da cobertura para ajuste ao espaçamento da cultura. A largura da cobertura foi de 3,0 m, e também de 3,0 m o comprimento dos arcos de ferro galvanizado, dispostos no parreiral a cada $2,5 \mathrm{~m}$, totalizando sete fileiras. $\mathrm{O}$ ponto mais alto da cobertura plástica ficou a uma distância de $0,90 \mathrm{~m}$ em relação às videiras.

Nas plantas cultivadas sob sombrite no sistema de capela, utilizou-se tela de polietileno preta, com $18 \%$ de retenção de fluxo de radiação solar, sustentada pelos fios de arame do sistema latada, sem a utilização de arcos.

Para a determinação da irrigação, dos tratos culturais e do controle fitossanitário foi usado o mesmo critério do experimento realizado em Uraí. Com relação às aplicaçóes de produtos fitossanitários, foram realizadas 16 e 78 aplicaçôes para o controle do míldio, nas videiras cultivadas sob cobertura plástica e sob sombrite respectivamente, de acordo com o critério do consultor que assiste a área.
As características químicas das bagas, como teor de sólidos solúveis (SS), acidez titulável (AT), índice de maturação (SS/AT) e pH, foram avaliadas semanalmente, a partir do início da maturação, caracterizada pelo início do amolecimento das bagas, até a colheita. Para tanto, foram selecionadas sete videiras representativas em cada sistema de cultivo protegido, sendo marcados dez cachos representativos em cada planta, das quais foram retiradas uma baga na parte superior, mediana e inferior do cacho, totalizando 30 bagas por planta. A colheita foi realizada em 28 de abril de 2009 em Uraí e em 14 de maio de 2010, em Marialva, com base no teor de SS, bem como no valor de mercado do produto.

O teor de SS foi determinado em refratômetro digital de bancada com compensação automática de temperatura (ModeloDR301-95, Krüss Optronic, Alemanha), por meio da trituração das amostras, e o resultado expresso em ${ }^{\circ}$ Brix. A determinação da $\mathrm{AT}$ e do $\mathrm{pH}$ foi realizada por titulação do suco com solução padronizada de $\mathrm{NaOH} 0,1 \mathrm{~N}$ em titulador potenciométrico digital (Modelo Tritoline Easy, Schott Geräte, Alemanha), adotando-se como ponto final da titulaçáo o $\mathrm{pH}=8,2$, e o resultado expresso em porcentagem de ácido tartárico (Instituto Adolfo Lutz, 1985). A evolução da maturação foi avaliada utilizandose a análise de regressáo e a determinação do grau da regressão que melhor se ajustou ao comportamento destas variáveis foi feita de acordo com o maior valor do coeficiente de determinação $\left(\mathrm{R}^{2}\right)$.

O delineamento experimental utilizado foi o inteiramente casualizado, com dois tratamentos e sete repetiçôes. As características químicas das bagas de cada safra, durante a colheita, foram analisadas por meio da análise do teste t de Student para amostras independentes, a 5\% de significância.

\section{RESULTADOS E DISCUSSÃO}

No experimento realizado em Uraí (PR), a evolução da maturação do teor de sólidos solúveis (SS), ocorreu de forma progressiva nos dois sistemas de cultivo protegido. No momento da colheita, aos 108 dias após a poda, não houve diferença entre os diferentes tipos de cultivo protegido para o teor de SS, registrando-se em média, 17,6 e 16,4 ${ }^{\circ}$ Brix, respectivamente, sob cobertura plástica e sob sombrite (Figura 1a). Ao considerar a colheita a 19,0 ${ }^{\circ}$ Brix, valor recomendado para a 'BRS Clara' por CAmargo et al. (2003), é possível antecipar a colheita em seis dias na cobertura plástica em relação ao sombrite, pois esta condição está estimada para ocorrer, respectivamente, aos 112 e 118 dias após a poda.

No vinhedo experimental localizado em Marialva (PR), houve aumento no teor de SS até a colheita nas videiras sob cobertura plástica e sob sombrite. No início da maturação, o teor de SS das videiras sob sombrite era 
(a)

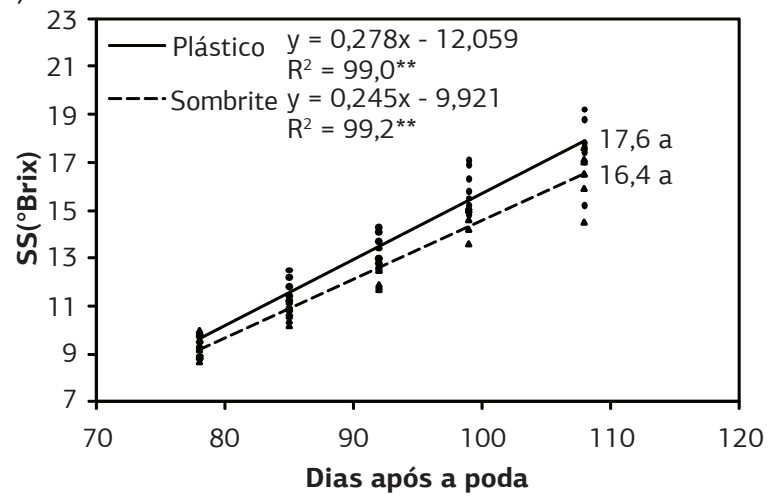

(b)

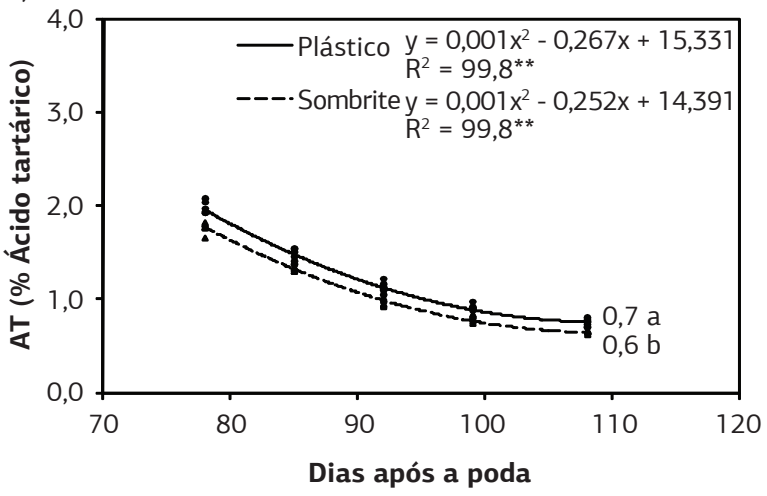

(c)

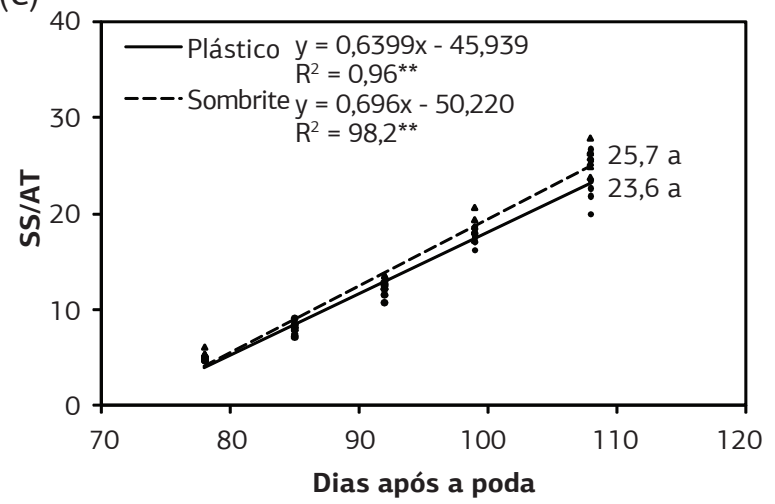

(d)

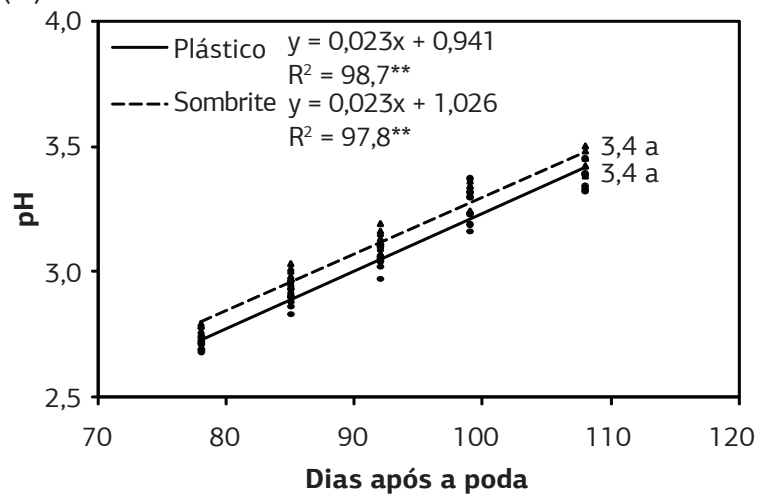

Figura 1. Evolução do teor de sólidos solúveis - SS (oBrix) (a), acidez titulável - AT (\% de ácido tartárico) (b), índice de maturação (SS/AT) (c) e pH (d), durante a maturação da videira 'BRS Clara' sobre o porta-enxerto IAC-766 'Campinas', submetida a diferentes tipos de cultivo protegido. Uraí (PR), 2009. Obs: Médias seguidas da mesma letra não diferem entre si pelo teste t de Student $(\mathrm{p}<0,05) .{ }^{* *}$ Significativo a $1 \%$ de probabilidade pelo teste $\mathrm{F}$.

maior, mas com o decorrer da maturação o aumento desta variável nas plantas sob cobertura plástica ocorreu de forma mais rápida (Figura 2a). No momento da colheita, aos 108 dias após a poda, o teor de SS foi maior nas videiras sob cobertura plástica (19,6 Brix), em relação ao sombrite (17,2 ${ }^{\circ}$ Brix). Nesta área experimental, é possível antecipar a colheita da 'BRS Clara' em seis dias nas videiras cultivadas sob cobertura plástica em relação às sob sombrite, estimada para ocorrer aos 120 e 126 dias após a poda respectivamente, de acordo com a análise de regressáo e ao considerar o ponto de colheita recomendado para esta cultivar.

De acordo com CAmargo et al. (2003), a uva 'BRS Clara’ possui elevados teores de SS, no fim da maturação, valores considerados superiores ao mínimo estabelecido para a comercialização de uvas finas de mesa do grupo 'Itália' na regiấo, que é de $14,0^{\circ}$ Brix (Mapa, 2002). No entanto, de acordo com os resultados observados neste trabalho, os frutos da 'BRS Clara' com teor de SS ao redor de $14,0^{\circ}$ Brix são inadequados para o consumo, devido à elevada acidez e ao sabor adstringente acentuado. Desta forma, sugere-se que a 'BRS Clara' seja colhida quando o teor de SS esteja, no mínimo, em torno de $16^{\circ}$ Brix.

Lulu et al. (2005), Detoni et al. (2007) e Chavarria et al. (2010) não observaram diferença significativa no teor de SS das uvas 'Romana' (A 1105), 'Cabernet Sauvignon' e 'Moscato Giallo' respectivamente, cultivadas sob cobertura plástica e a céu aberto. Entretanto, videiras da 'Cabernet Sauvignon' sobre diferentes porta-enxertos, em Jundiaí (SP), obtiveram maior teor de SS das bagas quando cultivadas a céu aberto (Ferreira et al., 2004).

Schideck et al. (1999) concluíram que o processo de maturação da uva 'Niágara Rosada', em Bento Gonçalves (RS), foi mais rápido no interior da estufa plástica, quando comparada àquelas cultivadas a céu aberto, em funçáo do maior valor de temperatura no interior da estufa. Chavarria et al. (2009a), ao avaliarem o comportamento fenológico da videira 'Moscato Giallo', em Flores da Cunha (RS), verificaram que as condiçôes de temperatura mais elevada no interior da cobertura plástica propiciaram a antecipação do início da brotação e reduziram a duração das fases fenológicas até o início da maturação. No entanto, a menor radiaçáo fotossinteticamente ativa, neste sistema, acarretou atraso no processo de maturação das uvas, quando comparado a céu aberto.

Quanto à acidez titulável (AT) (Figura 1b), nas videiras cultivadas em Uraí (PR), houve decréscimo nas médias no decorrer da maturação. No momento da colheita, as uvas cultivadas sob cobertura plástica tinham maior acidez $(0,7 \%)$, quando comparadas àquelas sob sombrite 
(a)

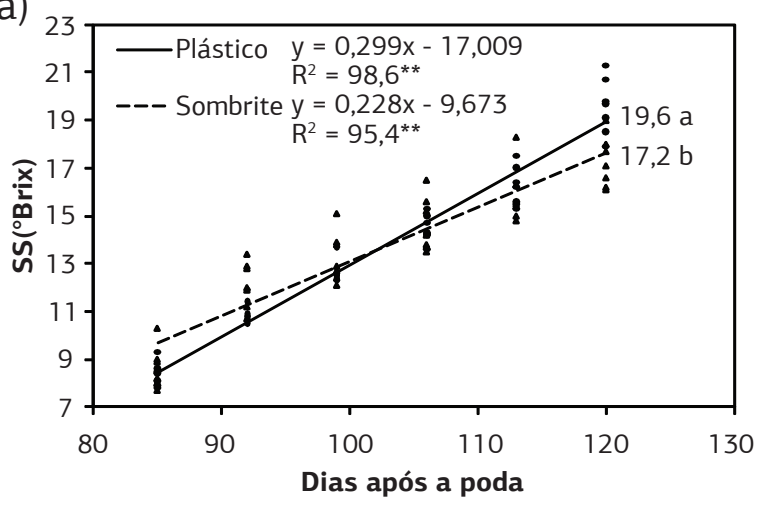

(b)

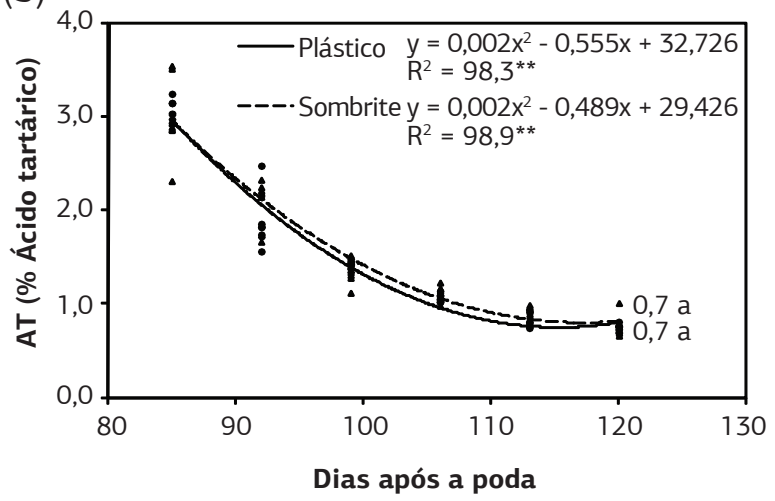

(c)

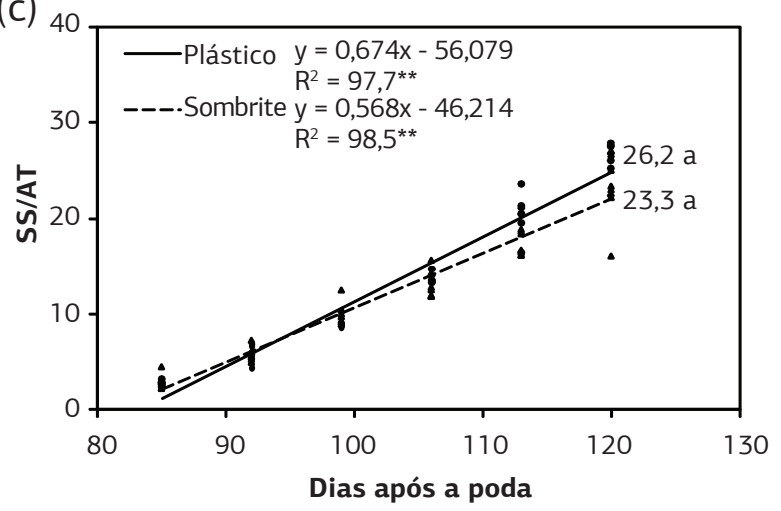

(d)

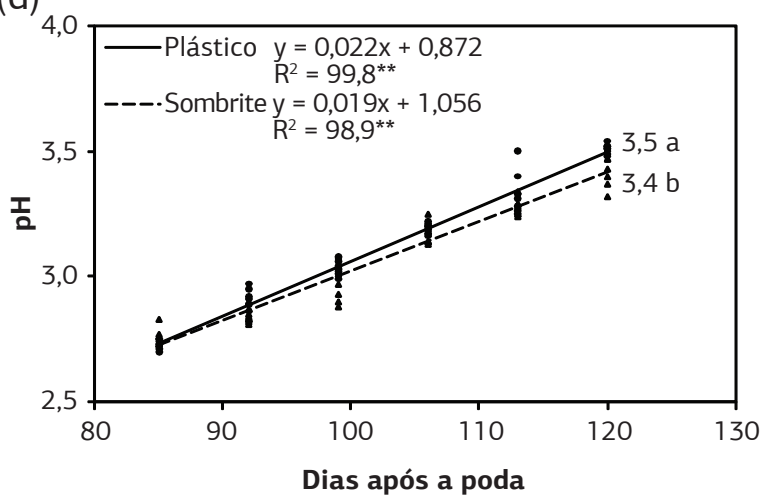

Figura 2. Evolução do teor de sólidos solúveis - SS (oBrix) (a), acidez titulável - AT (\% de ácido tartárico) (b), índice de maturação (SS/ AT) (c) e $\mathrm{pH}$ (d), durante a maturação da videira 'BRS Clara' sobre o porta-enxerto IAC-766 'Campinas', submetida a diferentes tipos de cultivo protegido. Marialva (PR), 2009. Obs: Médias seguidas da mesma letra náo diferem entre si pelo teste t de Student ( $<<0,05$ ). ** Significativo a $1 \%$ de probabilidade pelo teste $\mathrm{F}$.

$(0,6 \%)$. Segundo as equaçóes, o ponto mínimo de acidez foi obtido aos 109 dias após a poda com 0,7\% e 0,6\%, respectivamente, sob cobertura e sob sombrite.

Em Marialva (PR), observou-se a redução do teor de AT (Figura 2b), não sendo verificada diferença significativa entre os tipos de cultivo protegido quanto a essa variável no momento da colheita. De acordo com as equaçôes, o ponto mínimo de acidez nos dois sistemas de cultivo protegido foi de $0,7 \%$ aos 115 e 117 dias após a poda, respectivamente, sob cobertura plástica e sob sombrite.

Observa-se que a evolução de AT em ambas as áreas experimentais reduziu de forma gradativa, comportando-se de forma contrária ao teor de SS e $\mathrm{pH}$. Segundo Blouin e Guimberteau (2004) e Manfroi et al. (2004), no início da maturação, as bagas tinham elevado teor de AT, pois os principais ácidos das videiras (tartárico e málico) são sintetizados pelas folhas e pelas bagas ainda verdes. Porém, com a evolução da maturação, a concentração dos ácidos diminui, devido ao aumento da demanda por energia e sua utilização na respiração celular, além da diluição do mosto pela entrada de água no fruto.

Em estudo com a videira 'Moscato Giallo', em Flores da Cunha (RS), Chavarria et al. (2010) não observaram diferença para o teor de AT entre as áreas cobertas ou não com plástico. Detoni et al. (2007), ao avaliarem a uva
'Cabernet Sauvignon', em Toledo (PR), registraram maior teor de AT nas plantas sob cobertura plástica em relação às plantas cultivadas a céu aberto.

Durante o processo de maturação das uvas, o teor de SS aumenta e o de ácidos orgânicos diminui, sendo a concentraçáo de SS afetada, principalmente, pela temperatura do ar e pela disponibilidade hídrica do solo; assim, o aumento térmico favorece as condiçóes para a realizaçáo dos diferentes processos fisiológicos, como a transformação da sacarose em glicose e frutose (Schiedeck et al., 1999; Benato, 2003). No estádio inicial de desenvolvimento do fruto, a temperatura ótima para a síntese de ácidos varia entre 20 e $25^{\circ} \mathrm{C}$, e durante a maturação, a temperatura em torno de $27^{\circ} \mathrm{C}$ é considerada propícia. Desta forma, os frutos que amadurecem sob condiçôes de baixas temperaturas possuem maiores valores de acidez total quando comparados aos que amadurecem sob condiçóes de temperaturas elevadas (KisHino et al., 2007; Moura et al. 2009).

De acordo com SATO et al. (2009), além do teor de SS e AT, o índice de maturação e o pH devem ser observados na evolução da maturação, pois estấo diretamente relacionadas à qualidade das uvas. Observa-se na figura 1c que a evolução do índice de maturação (SS/AT) aumentou gradativamente até o momento da colheita em Uraí (PR). 
Para esse índice não houve diferença entre os sistemas de cultivo protegido, registrando-se, em média, 24,7.

Em Marialva (PR), o índice de maturação seguiu a tendência de crescimento progressivo (Figura 2), não havendo diferença entre a cobertura plástica e o sombrite, sendo obtidos por ocasiáo da colheita, em média, 26,2 e 23,3 respectivamente.

Segundo CAmargo et al. (2003), a 'BRS Clara' possui elevado potencial glucométrico, chegando a mais de 20,0 oBrix, sendo o índice de maturaçáo em torno de 24,0 no momento da colheita.

Em estudo realizado com a videira 'Niágara Rosada', em Bento Gonçalves (RS), Schideck et al. (1999) constataram o aumento do índice de maturação (SS/AT) durante o processo de maturação, com oscilaçôes nos tratamentos a céu aberto, em vista das precipitaçôes pluviais. O índice de maturação pode auxiliar na determinação do ponto ideal de colheita das uvas, uma vez que representa o equilíbrio entre o teor de açúcar e a acidez. Por se tratar de uma relação de evolução inversa entre SS e AT, o índice de maturação tende a apresentar semelhança em relação à evolução do teor de SS, ou seja, com baixos teores no início da maturação e aumento progressivo até o período próximo à colheita (SATO et al., 2009).

Em relação ao $\mathrm{pH}$, observa-se o aumento progressivo em seu teor em Uraí (PR) (Figura 1), não havendo diferenças significativas entre os sistemas de cultivo protegido no momento da colheita, registrando-se, média de 3,4.

No vinhedo em Marialva (PR), houve crescimento progressivo do $\mathrm{pH}$ (Figura 2), com valor médio observado no momento da colheita dessa variável superior nas videiras cultivadas sob cobertura plástica $(3,5)$ em comparação às cultivadas sob sombrite $(3,4)$.

МотA et al. (2006) relataram que o aumento do $\mathrm{pH}$ durante a maturação interfere na formação de sais ácidos, sendo a relação entre sais ácidos e ácido livre influenciada pela quantidade total de calor efetivo durante a maturação. Em estudo realizado por SCHideck et al. (1999), Detoni et al. (2007) e Chavarria et al. (2008), os valores de $\mathrm{pH}$ foram inferiores nas videiras cultivadas sob cobertura plástica em comparação àquelas a céu aberto, indicando que a variação nos resultados pode ocorrer em função da cultivar avaliada.

Com base nos resultados, pôde-se observar que o uso da cobertura plástica, permitiu a antecipação da colheita da videira 'BRS Clara' em seis dias em relação ao sombrite, além de não alterar as principais características químicas das bagas e propiciar a obtenção de frutos de melhor qualidade durante a safra fora de época; este período é caracterizado por condiçóes de alta temperatura e umidade relativa do ar, favorável à ocorrência de doenças, como o míldio. Desta forma, possibilitará ao produtor o escalonamento da colheita, que poderá ser realizada no momento em que considerar mais propício à venda do produto. Estes fatores possibilitam o aumento da competitividade das uvas sem semente produzidas nesta regiáo. Entretanto, o cultivo protegido é um sistema novo de produção de uvas de mesa e alguns aspectos importantes devem ser avaliados, tendo em vista a menor durabilidade do plástico, em média três anos, quando comparado ao sombrite, que tem a durabilidade de 15 anos.

\section{CONCLUSÃO}

O uso da cobertura plástica permite a antecipação da colheita em seis dias em relação ao sombrite e não altera o índice de maturação das bagas da videira 'BRS Clara' durante a safra fora de época, no Norte do Paraná.

\section{REFERÊNCIAS}

BENATO, E.A. Tecnologia, fisiologia e doenças pós-colheita de uvas de mesa. In: POMMER, C.V. Uva: tecnologia de produção, pós-colheita, mercado. Porto Alegre: Cinco Continentes, 2003. p.635-777.

BLOUIN, J.; GUIMBERTEAU, G. Maduración y madurez de la uva. Madrid: Mundi-Prensa, 2004. 151p.

CAMARGO, U.A.; NACHTIGAL, J.C.; MAIA, J.D.G.; OLIVEIRA, P.R.D.; PROTAS, J. F.S. BRS Clara: nova cultivar de uva branca de mesa sem semente. Bento Gonçalves: Embrapa Uva e Vinho, 2003. 4p. (Comunicado Técnico, 46)

CAVIGLIONE, J.H.; KIIHL, L.R.B.; CARAMORI, P.H.; OLIVEIRA, D. Cartas climáticas do Paraná. Londrina: IAPAR, 2000. (CD-ROM)

CHAVARRIA, G.; SANTOS, H.P.; MANDELLI, F.; MARODIN, G.A.B.; BERGAMASCHI, H.; CARDOSO, L.S. Caracterização fenológica e requerimento térmico da cultivar Moscato Giallo sob cobertura plástica. Revista Brasileira de Fruticultura, v.31, p.119126, 2009a.

CHAVARRIA, G.; SANTOS, H.P.; MANDELLI, F.; MARODIN, G.A.B.; BERGAMASCHI, H.; CARDOSO, L.S. Potencial produtivo de videiras cultivadas sob cobertura de plástico. Pesquisa Agropecuária Brasileira, v.44, p.141-147, 2009b.

CHAVARRIA, G.; SANTOS, H. P.; ZANUS, M.C.; MARODIN, G.A.B.; CHALAÇA, M.Z.; ZORZAN, C. Maturação de uvas Moscato Giallo sob cultivo protegido. Revista Brasileira de Fruticultura, v.32, p.151-160, 2010.

CHAVARRIA, G.; SANTOS, H.P.; ZANUS, M.C.; ZORZAN, C.; MARODIN, G.A.B. Caracterização físico-química do mosto e do vinho Moscato Giallo em videiras cultivadas sob cobertura de plástico. Pesquisa Agropecuária Brasileira, v.43, p.911-916, 2008.

COLOMBO, L.A.; ASSIS, A.M.; SATO, A.J.; TESSMANN, D.J.; GENTA, W.; ROBERTO, S.R. Produção fora de época da videira 'BRS Clara' sob cultivo protegido. Ciência Rural, v.41, p.212-218, 2011. 
DETONI, A.M.; CLEMENTE, C.; FORNARI, C. Produtividade e qualidade da uva 'Cabernet Sauvignon' produzida sob cobertura de plástico em cultivo orgânico. Revista Brasileira de Fruticultura, v.29, p. 530-534, 2007.

FERREIRA, M.A.; PEDRO JÚNIOR, M.J.; SANTOS, A.O.; HERNANDES, J.L. Modificação parcial do ambiente de cultivo da videira 'Cabernet Sauvignon' sobre diferentes porta-enxertos: efeito sobre a produção e o teor de sólidos solúveis. Bragantia, v.63, p.439-445, 2004.

GENTA, W.; TESSMANN, D.J.; ROBERTO, S.R.; VIDA, J.B.; COLOMBO, L.A. SCAPIN, C.R.; RICE, W.S.; CLOVIS, L.R. Manejo de míldio no cultivo protegido de videira de mesa 'BRS Clara'. Pesquisa Agropecuária Brasileira, v.45, p.13881395, 2010.

IBGE - Instituto Brasileiro de Geografia e Estatística. Produçáo agrícola municipal. 2009. Disponível em: <http://www.sidra.ibge. gov.br/bda/tabela/protabl.asp? $\mathrm{c}=1613 \& \mathrm{z}=\mathrm{t} \& \mathrm{o}=3 \& \mathrm{i}=\mathrm{P}>$. Acesso em: $24 / 12 / 2010$.

INSTITUTO ADOLFO LUTZ. Normas analíticas do Instituto Adolfo Lutz: métodos químicos e físicos para análise dos alimentos. 3.ed. São Paulo: Instituto Adolfo Lutz, 1985, v.1, 371p.

KISHINO, A.Y.; CARVALHO, S.L.C.; ROBERTO, S.R. Viticultura tropical: o sistema de produção do Paraná. Londrina: IAPAR, 2007. 366p.

LULU, J.; CASTRO, J.V.; PEDRO JÚNIOR, M.J. Efeito do microclima na qualidade da uva de mesa 'Romana' (A 1105) cultivada sob cobertura plástica. Revista Brasileira de Fruticultura, v.27, p.422-425, 2005.

MANFROI, L.; MIELE, L.; RIZZON, L.A.; BARRADAS, C. I. N.; SOUZA, P. V. D. Evolução da maturação da uva Cabernet
Franc conduzida no sistema lira aberta. Ciência e Agrotecnologia, v.28, p.306-313, 2004.

MAPA - MINISTÉRIO DA AGRICULTURA, PECUÁRIA E ABASTECIMENTO. Instruçáo normativa n. ${ }^{\circ} 1$ de $1^{\circ}$ de fevereiro de 2002. Regulamento técnico de identidade e de qualidade para a classificação da uva fina de mesa. Diário Oficial da República Federativa do Brasil, Brasília, 04 fev. 2002, Seção 1. 7p.

MOTA, R.V.; REGINA, M.A.; AMORIM, D.A.; FÁVERO, A.C. Fatores que afetam a maturaçáo e a qualidade da uva para vinificação. Informe Agropecuário, v.27, p.56-64, 2006.

MOURA, M.S.B.; TEIXEIRA, A.H.C.; SOARES, J.M. Exigências Climáticas. In: SOARES, J.M.; LEÂO, P. C. de S. A Vitivinicultura no Semiárido Brasileiro. Brasília, DF: Embrapa Informação Tecnológica; Petrolina: Embrapa Semi-Árido, 2009. p.36-69.

NAVES, R.L.; TESSMANN, D.J.; GARRIDO, L.R.; SÔNEGO, O.R. Doenças e seu controle. Embrapa Uva e Vinho. Sistemas de produção, 2005. Disponível em: <http://sistemasdeproducao. cnptia.embrapa.br/FontesHTML/Uva/MesaNorteParana/doencas. htm/>. Acesso em: 22 abr. 2009.

NOVELLO, V.; PALMA, L. Growing grapes under cover. Acta Horticulturae, n.785, p.353-362. 2008.

SATO, A.J.; SILVA, B.J.; BERTOLUCCI, R.; CARIELO, M.; GUIRAUD, M.C.; FONSECA, I.C.B.; ROBERTO, S.R. Evolução da maturação e características físico-químicas de uvas da cultivar Isabel sobre diferentes porta-enxertos. Semina: Ciências Agrárias, v.30, p.11-20, 2009.

SCHIEDECK, G.; MIELE, A.; BARRADAS, C.I.N.; MANDELLI, F. Maturação da uva 'Niágara Rosada' cultivada em estufa de plástico e a céu aberto. Ciência Rural, v.29, p.625-633, 1999. 